\title{
Satellite-derived UV climatology at Escudero Station, Antarctic Peninsula
}

\author{
RAUL R. CORDERO ${ }^{1}$, ALESSANDRO DAMIANI ${ }^{1}$, GUNTHER SECKMEYER ${ }^{2}$, STEFAN RIECHELMANN ${ }^{2}$, \\ FERNANDO LABBE ${ }^{3}$, DAVID LAROZE ${ }^{4,5}$ and FERNANDA GARATE ${ }^{1}$ \\ ${ }^{1}$ Universidad de Santiago de Chile, Ave Bernardo O'Higgins 3363, Santiago, Chile \\ ${ }^{2}$ Leibniz Universität Hannover, Herrenhäuser Str. 2, 30419 Hannover, Germany \\ ${ }^{3}$ Universidad Técnica Federico Santa María, Ave España 1680, Valparaíso, Chile \\ ${ }^{4}$ Instituto de Alta Investigación, Universidad de Tarapacá, Casilla 7D, Arica, Chile \\ ${ }^{5}$ Max Planck Institute, 55021 Mainz, Germany \\ raul.cordero@usach.cl
}

\begin{abstract}
We have used data from the Ozone Monitoring Instrument (OMI) aboard NASA's Earth Observing System (EOS) Aura satellite over the period 2004-11 to describe the characteristics of surface ultraviolet (UV) irradiance at Escudero Station $\left(62^{\circ} 12^{\prime} \mathrm{S}, 58^{\circ} 57^{\prime} \mathrm{W}\right)$. The station is located on King George Island (northern Antarctic Peninsula). Temperatures in summer are frequently above $0^{\circ} \mathrm{C}$, and the surrounding ocean is typically ice-free. We found that the UV irradiance at Escudero is driven by the Antarctic ozone hole (which annually in spring leads to significant variations in the ozone) and by clouds (which are more frequent and have a larger optical depth compared with other Antarctic sites). The combined effect of ozone and clouds led to significant variations in the surface UV. The variability (taken as the standard deviation of the UV estimates retrieved from OMI) is typically greater than $30 \%$ at Escudero, but may reach values greater than $50 \%$ in spring. The consistency of OMI-derived data was checked by using ground-based spectral measurements carried out under controlled conditions in January 2011.
\end{abstract}

Received 29 June 2012, accepted 8 January 2013, first published online 28 March 2013

Key words: OMI, ozone, satellite retrievals, UV irradiance, UV spectroradiometry

\section{Introduction}

Mostly due to the action of ozone depleting substances (ODSs), global atmospheric column ozone amounts decreased over the decades from the 1970s to the 1990s, with a decrease amounting to $3.5 \%$ between average 1964-80 and 2002-05 values (WMO 2011). Springtime Antarctic total column ozone losses (the so-called ozone hole), first recognizable around 1980 (Farman et al. 1985), is the clearest manifestation of the effect of ODSs on the ozone layer (WMO 2011).

Antarctic ozone depletion far exceeds natural variability and has occurred without exception since 1980. Springtime Antarctic ozone levels slowly decreased in the 1970s and exhibited rapid decreases in the 1980s and early 1990s. In the $14-20 \mathrm{~km}$ layer of the Antarctic stratosphere, where most of the ozone resides, virtually all of the ozone is now destroyed every year in the late August to early October period (WMO 2011, Flemming et al. 2011).

In the Antarctic plateau, large ozone losses lead to a significant increase in surface UVB radiation (290-315 nm). Ground-based measurements show that the average spring erythemal irradiance (computed by using the so-called McKinlay \& Diffey (1987) erythema action spectrum) for $1990-2006$ is up to $85 \%$ greater than the modelled irradiance for 1963-80 (Bernhard et al. 2010). Although surface UV in
Antarctica is driven by ozone, both cloudiness and ground reflectivity (albedo) also have a significant influence.

In general, cloud transmission is the greatest and most changeable atmospheric factor affecting the variability of surface UV. In the Antarctic Peninsula, heavily overcast conditions can reduce surface UV irradiance by $90 \%$ (e.g. Bernhard et al. 2005). Consequently, significant efforts have been made to assess the cloudiness effect on surface UV at high latitude locations (e.g. Laska et al. 2010, 2011).

Moreover, high surface albedo (reflectivity) greatly enhances surface UV in areas where there is extensive snow and/or ice cover (e.g. Ialongo et al. 2011). Enhancements of erythemal UV of about $20 \%$ are expected in regions with snow cover, but even greater enhancements have been seen in Antarctica due to very clean, high albedo over large areas (WMO 2011).

In this paper, we describe some of the characteristics of the surface UV at Escudero Station ("Base Profesor Julio Escudero", $\left.62^{\circ} 12^{\prime} \mathrm{S}, 58^{\circ} 57^{\prime} \mathrm{W}\right)$. The station is located on King George Island (northern Antarctic Peninsula). The local UV climate is influenced by a mix of surface conditions around the station, including open ocean, mountains, glaciers, and dark rock, such that surface albedo shows a significant change through the year with highest values in winter. Moreover, yearlong atmospheric 
depression centres play an important role in air mass circulation (Angiel et al. 2010). The frequent passage of low-pressure systems affects the area surrounding King George Island such that clouds are more frequent and have a larger optical depth compared with other Antarctic sites (Choi et al. 2008). For UV climatology at other Antarctic sites, see Bernhard et al. (2004, 2005, 2006).

Most of our conclusions are based on estimates retrieved from the Ozone Monitoring Instrument (OMI) aboard NASA's EOS (Earth Observing System) Aura satellite. However, we also report on ground-based UV measurements at Escudero Station. These quality-controlled spectral measurements were carried out in January 2011 by using a double monochromatorbased spectroradiometer. The instrument was taken to the Antarctic Peninsula during a campaign meant to gather information on the effect of albedo and clouds on surface UV. Additional details are provided below.

\section{Background}

\section{Satellite estimates}

The surface UV irradiance can be derived from satellite readings. Recent validation of satellite estimates have been focused on OMI data, which have been compared to ground-based measurements (Tanskanen et al. 2006, 2007a, Weihs et al. 2008, Buchard et al. 2008). All found that the OMI-derived products are biased high, particularly at polluted sites.

Differences with ground-based data are often linked with the limited spatial resolution. Satellite measurements represent a much larger region (OMI minimum pixel at nadir is $13 \times 24 \mathrm{~km}^{2}$ ) than ground-based measurements. Groundbased measurements of UV erythemal dose at various sites within a single OMI satellite pixel have showed deviations of $\pm 5 \%$ among them under cloud-free conditions, or $20 \%$ when including urban areas (Weihs et al. 2008). Under partly cloudy conditions and overcast conditions the discrepancy between the stations can exceed 200\%. If three-hourly averages are considered, the agreement is better than $20 \%$ within a distance of $10 \mathrm{~km}$ (Weihs et al. 2008). This spatial discrepancy can explain most of the differences between ground-based and satellite data but cannot explain a strong systematic bias.

The OMI overestimation of ground-based UV measurements may be partly explained by the lack of sensitivity of satellite instruments to the boundary layer (Weihs et al. 2008, Buchard et al. 2008). However, over snow-covered surfaces the OMI-derived dose is generally lower than the ground-based measurement because the OMI algorithm uses climatological surface albedo that may then be lower than the actual effective surface albedo (Tanskanen et al. 2007b, WMO 2011). Part of the problem is that a portion of the observed reflectivity may be incorrectly interpreted as cloud cover, which reduces the estimated irradiance. All-sky conditions and snow-free data have been compared separately to evaluate the albedo effect. For example, a comparison by Buchard et al. (2008) found that OMI overestimates erythemal daily doses by $14 \%$ for days without snow and only by $8 \%$ if days with snow are included in the comparison.

It is also worth highlighting the effect of high solar zenith angles (SZA) on the nadir-viewing instruments. It occurs especially when satellites record data at high latitudes around winter periods. This effect leads to a seasonal dependence in the satellite data that becomes evident when comparing satellite readings with groundbased data. Nevertheless, it is usually more evident in the case of algorithms based on Differential Optical Absorption Spectroscopy (DOAS) while it is negligible in the case of the most recent versions of the OMI-TOMS (Total Ozone Mapping Spectrometer) dataset (e.g. Damiani et al. 2012). In this analysis we used the most recent versions of the OMI-TOMS dataset (see OMI-derived data).

\section{Modelled UV data}

The surface UV irradiance can also be calculated by solving the equation of radiative transfer that governs the transfer of radiant energy in the atmosphere. Indeed, radiative transfer models allow calculation of the surface UV irradiance from some set of measured input parameters linked with the surface reflectivity, the SZA, the total ozone column as well as the spectral characteristics of clouds and aerosols. These calculations provide the hypothetical irradiance that would be measured if input parameters were known.

Model outcomes strongly depend on the quality of the inputs. If quality-assured inputs are available, the standard uncertainties of model outcomes under cloudless conditions can be up to $9 \%$ in the case of clean sites, and up to $20 \%$ in the case of sites with very large aerosol load (Cordero et al. 2007).

Problems due to the characterization of the cloud effect complicate the assessment of surface UV irradiance by using radiative transfer models. However, model outcomes have been shown to be very useful in order to check the consistency of ground-based measurements. For example, a comparison with results of a radiative transfer model confirmed that long-term ground-based measurements carried out at Palmer Station and at McMurdo Station in Antarctica are consistent to within $\pm 5 \%$ (Bernhard et al. 2005).

\section{Ground-based spectral UV measurements}

The spectrally resolved UV irradiance can be efficiently measured by using double monochromator-based spectroradiometers. In order to ensure the quality of ground-based spectral measurements, the international Network for the Detection of Atmospheric Composition 
Change (NDACC) and the World Meteorological Organization (WMO) have defined a set of strict specifications (see Seckmeyer et al. 2001). Attending to the influence of the uncertainty sources affecting spectral measurements, offset suppression, noise minimization, stray light counteraction and radiometric stability, are among the required specifications. The latter is the most important requirement for trend detection, it can be determined by repeated checks against standard lamps (see Cordero et al. 2008).

While sensor stability is the principal requirement for trend detection, absolute calibration is required when comparing measurements at different locations, or between different techniques (e.g. ground vs satellite). The absolute accuracy of NDACC-certified instruments has been validated by the systematic comparison of spectral UV measurements (under cloudless conditions) with spectral UV calculations, and by intercomparison campaigns that involved several instruments. Gröbner et al. (2006) showed results of the intercomparison of 25 European spectroradiometers relative to a transportable reference spectroradiometer. Almost half of the instruments had absolute agreement with the reference spectroradiometer to within $\pm 4 \%$ in the UV part of the spectrum. Most of the differences between the compared spectra can be explained by the involved uncertainties. Cordero et al. (2008) estimated that spectral UV measurements carried out by using these state-of-the-art spectroradiometers have an overall expanded uncertainty of up to $9 \%$.

Spectral UV series can be exploited in order to compute the UV index (UVI). This is an international standard measure of the UV level that can lead to an erythemal or sunburning response in humans. The UVI is evaluated by using the so-called McKinlay \& Diffey (1987) erythema action spectrum and multiplying it by 40 (WHO 2002). The expanded uncertainties when computing the UV index from spectral measurements carried out by using a NDACC-certified instrument, can be up to $10 \%$ (Cordero et al. 2008).

Ground-based UV series are limited worldwide. The NDACC maintains a long-term database of quality-assured UV data from a small number of observation sites. In Antarctica UV irradiance has been monitored for almost two decades by a network of spectroradiometers established by the US National Science Foundation (Bernhard et al. 2010).

Based on ground-based measurements, the UV climatology at Palmer Station (Bernhard et al. 2005), at McMurdo Station (Bernhard et al. 2006) and at South Pole Station (Bernhard et al. 2004) has been established. However, due to the lack of ground-based time series, other datasets (satellite-derived data for example) are required to assess the influence of factors that determine the surface UV at other sites.

\section{Data sources}

\section{OMI-derived data}

The NASA EOS OMI is one of the four instruments on the Aura satellite, launched on 15 July 2004 to a sunsynchronous near polar orbit with a $13 \mathrm{~h} 45$ local time (LT)
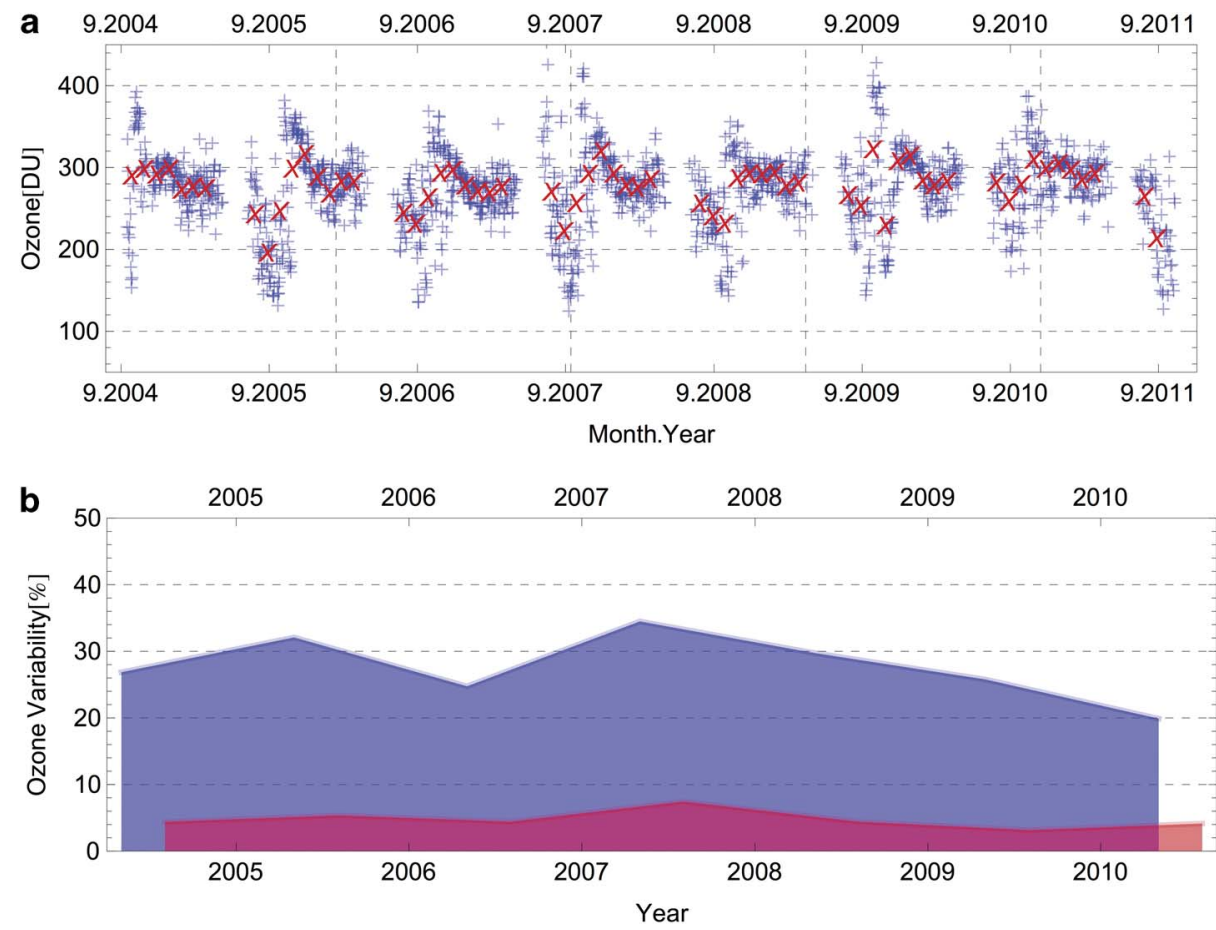

Fig. 1. a. Ozone Monitoring Instrument (OMI)-derived estimates of the total ozone column at Escudero. The number 9 in the axis labels denotes September. Blue crosses indicate the daily ozone estimates at Escudero and red crosses the monthly averages. b. Variability of the total ozone column at Escudero computed for October (blue line) and for January (red line). The variability was taken as being equal to the standard deviation of the daily estimates retrieved from OMI. 
Table I. UV climatology at Escudero Station computed by using the Ozone Monitoring Instrument (OMI)-derived data over the period $2004-11$. The variability was taken as being equal to the standard deviation of the OMI-derived values.

\begin{tabular}{|c|c|c|c|c|c|c|c|c|c|c|c|c|}
\hline & & Jan & Feb & March & April & May & July & Aug & Sept & Oct & Nov & Dec \\
\hline Ozone & Average & 293 & 277 & 276 & 280 & 284 & 290 & 260 & 233 & 266 & 284 & 305 \\
\hline (DU) & Variability & 18 & 20 & 19 & 24 & 17 & 29 & 41 & 49 & 79 & 58 & 25 \\
\hline \multirow{3}{*}{$\begin{array}{l}\text { UVI } \\
\text { (Clear-sky) }\end{array}$} & Average & 6.53 & 4.77 & 2.53 & 0.86 & 0.25 & 0.18 & 0.59 & 2.29 & 4.44 & 6.55 & 6.81 \\
\hline & Variability & 0.58 & 0.79 & 0.69 & 0.31 & 0.07 & 0.04 & 0.26 & 1.08 & 1.51 & 2.02 & 0.73 \\
\hline & Variability $(\%)$ & 9 & 16 & 27 & 36 & 29 & 21 & 44 & 47 & 34 & 31 & 11 \\
\hline \multirow{2}{*}{ UVI } & Variability & 1.16 & 0.90 & 0.60 & 0.22 & 0.05 & 0.04 & 0.17 & 0.68 & 1.05 & 1.67 & 1.25 \\
\hline & Variability (\%) & 34 & 38 & 46 & 53 & 24 & 25 & 54 & 59 & 44 & 47 & 33 \\
\hline \multirow{3}{*}{$\begin{array}{l}\text { CMF } \\
\text { (UVI-based) }\end{array}$} & Average & 0.52 & 0.49 & 0.51 & 0.49 & 0.82 & 0.96 & 0.55 & 0.51 & 0.54 & 0.54 & 0.56 \\
\hline & Variability & 0.17 & 0.18 & 0.18 & 0.17 & 0.23 & 0.15 & 0.20 & 0.19 & 0.17 & 0.16 & 0.18 \\
\hline & Variability (\%) & 33 & 36 & 35 & 34 & 28 & 15 & 37 & 38 & 32 & 30 & 32 \\
\hline \multirow{2}{*}{ Albedo } & Variability & 0.01 & 0.01 & 0.01 & 0.01 & 0.04 & 0.05 & 0.02 & 0.02 & 0.02 & 0.02 & 0.01 \\
\hline & Variability (\%) & 18 & 15 & 10 & 16 & 36 & 22 & 8 & 12 & 16 & 19 & 17 \\
\hline
\end{tabular}

$\mathrm{UVI}=\mathrm{UV}$ index, $\mathrm{CMF}=$ cloud modification factor, $\mathrm{LER}=$ Lambertian equivalent reflectivity.

ascending equator-crossing time. It is a contribution of the Netherlands' Agency for Aerospace Programs in collaboration with the Finnish Meteorological Institute.

The OMI instrument is a nadir viewing UV spectrometer that is currently continuing the long-term ozone measurements by NASA's TOMS instrument. It measures the solar reflected and backscattered radiation in the wavelength range from $270-500 \mathrm{~nm}$ with a spectral resolution of $0.55 \mathrm{~nm}$ in the UV and $0.63 \mathrm{~nm}$ in the visible. These measurements are used to retrieve the total ozone column (the total column amount of ozone from the surface to the top of the atmosphere), aerosol and cloud cover characteristics, surface UV irradiance and gas traces. The instrument has a $2600 \mathrm{~km}$ wide viewing swath. The ground pixel size at nadir position is $13 \times 24 \mathrm{~km}$ (along $\mathrm{x}$ across track) for total ozone column. It is capable of daily global mapping.

For our purposes we retrieved the total ozone column at Escudero Station from the OMI/Aura Total Ozone Column dataset (referred to as OMTO3). These products are rendered by the TOMS version 8.5 (v8.5) algorithm, which is an extension of the TOMS v8 algorithm. The description of the TOMS v8 algorithm can be obtained from the OMI Algorithm Theoretical Basis Document (ATBD) available at http://toms.gsfc.nasa.gov/version8/ v8toms_atbd.pdf. The treatment of clouds is the main difference between the TOMS $\mathrm{v} 8$ and the OMTO3 v8.5 algorithms. Old versions of OMTO3 and TOMS v8 data use a cloud pressure climatology based on thermal infrared cloud-top pressures. Now, OMTO3 v8.5 uses Optical Centroid Cloud Pressure derived by the rotational Raman scattering method. In this way the ozone retrieval is significantly improved and the so-called "ghost column" (i.e. the tropospheric ozone below the cloud cover not visible to the satellite) results substantially decreased (see also the updated OMTO3 README file available at NASA Goddard Earth Sciences (GES) Data and Information Services Center (DISC), http://disc.sci.gsfc.nasa.gov/).

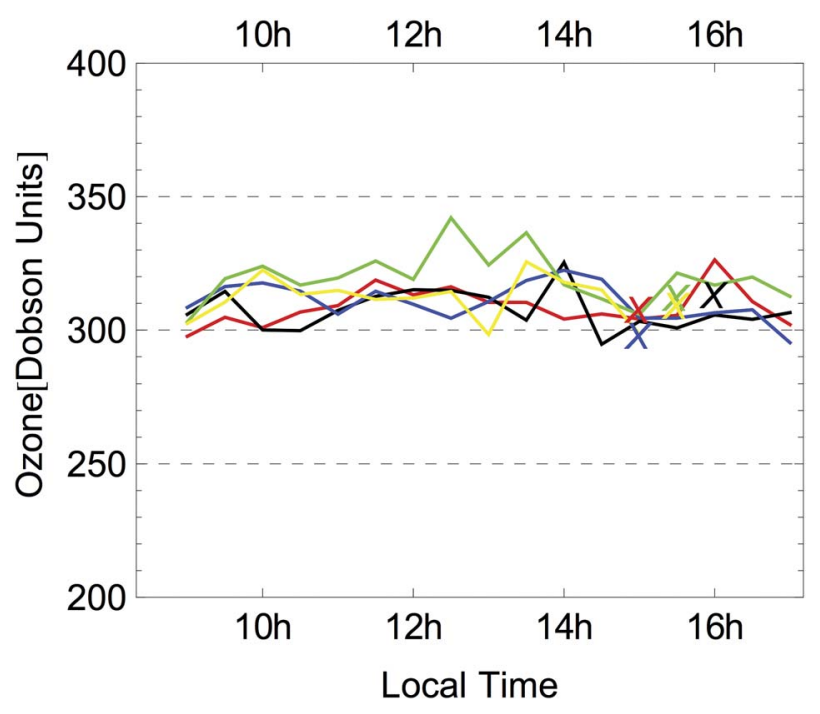

Fig. 2. Lines indicate total ozone column retrieved from ground-based measurements at Escudero Station. Crosses indicate ozone estimates retrieved from Ozone Monitoring Instrument (OMI). Colour indicates the dates: 21 January (red), 22 January (black), 23 January (blue), 24 January (green), 25 January (yellow). 


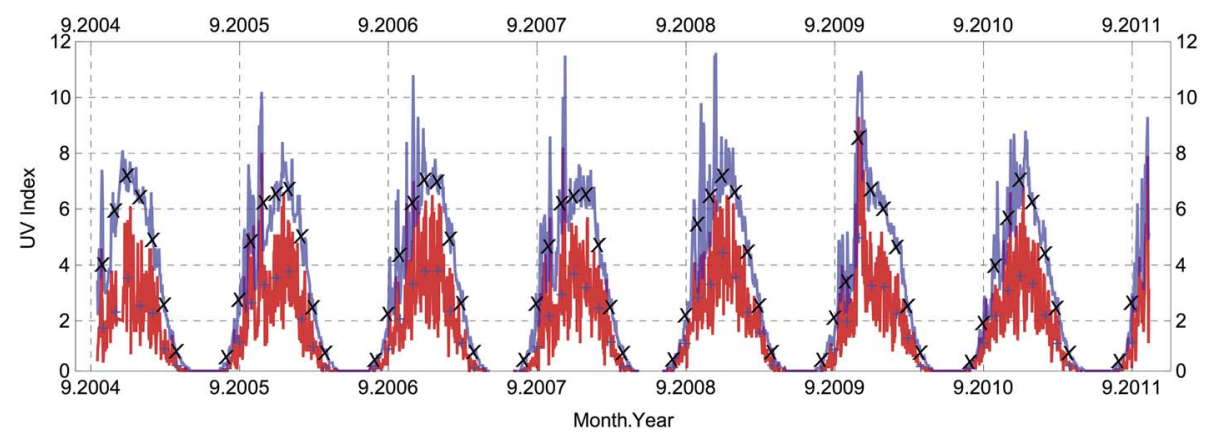

Fig. 3. Noontime UV index (UVI) at Escudero retrieved from Ozone Monitoring Instrument (OMI) readings. The number 9 in the axis labels denotes September. The blue line shows the daily estimates of UVI at Escudero retrieved assuming cloudless conditions, and the red line the daily estimates of UVI retrieved under all-sky conditions; the blue crosses and the black crosses indicate the monthly averages of the OMI-derived data under all-sky conditions and under clear-sky conditions, respectively.

Moreover, we also retrieved UV estimates at Escudero from OMUVB products. Surface UV estimates are determined by using an extension of the TOMS UV algorithm developed by NASA Goddard Space Flight Center (Tanskanen et al. 2006). Firstly, the algorithm estimates the surface irradiance assuming clear-sky conditions by using OMI total ozone column and climatological surface albedo (Tanskanen 2004) as input parameters. Then, in order to determine actual surface irradiance, the clear-sky irradiance is adjusted by using the cloud modification factor (CMF) that accounts for the attenuation of UV radiation due to clouds and non-absorbing aerosols. This retrieval procedure allowed us to analyse separately ozone and cloud influence on the surface UV irradiance. As shown below, we first analysed only the UV estimates computed assuming clear-sky conditions (see UV index), then we analysed the UV estimates under all-sky conditions (see Cloud effect).

\section{UVSPEC-computed data}

In order to compute the spectral UV irradiance at Escudero under clear-sky conditions, we used the libRadtran software package. This is a set of programs for radiative transfer calculations whose main tool is the UVSPEC model (Mayer \& Kylling 2005). The pseudospherical version of the DISORT solver, as described by Dahlback \& Stamnes (1991), was selected as radiative transfer solver.

The UVSPEC model allows calculation of the spectral UV from a set of measured input quantities linked with the concentration of atmospheric constituents (such as the ozone), the surface reflectivity as well as the spectral characteristics of aerosols. When computing the UV spectra by using the UVSPEC, the extra-terrestrial spectrum was quoted from Gueymard (2004), total ozone column was retrieved from OMI (see OMI-derived data), aerosols extinction was characterized by using Ångström's turbidity formula according to Bernhard et al. (2005), the Ångström coefficients $\alpha$ and $\beta$ were set to be 1.0 and 0.0125 , respectively. Effective surface albedo (the albedo of a uniform Lambertian surface that when used as input into a 1-D model reproduces the measured spectrum) was estimated from clear-sky measured spectra. Although the albedo for snow-covered surfaces can
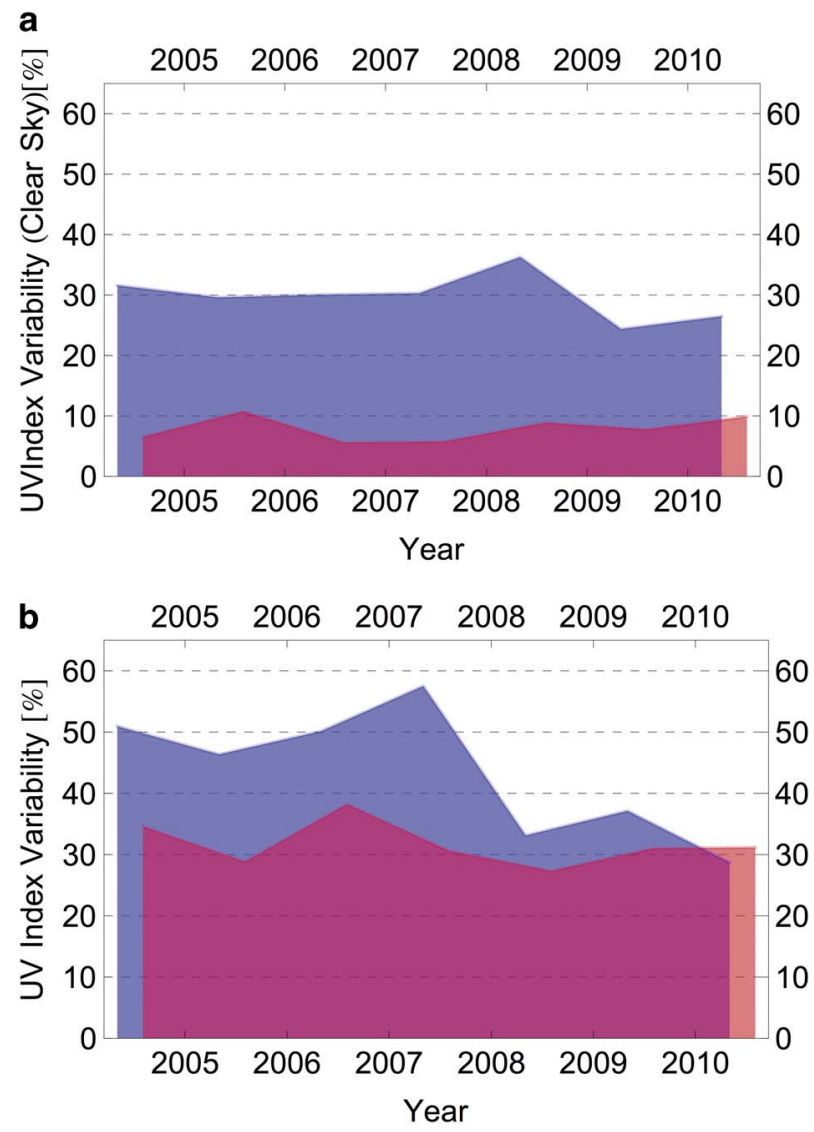

Fig. 4. Variability of the UV index (UVI) estimates at Escudero for October (blue line) and for January (red line). The variability was taken as being equal to the standard deviation of the daily estimates retrieved from Ozone Monitoring Instrument (OMI). a. Variability computed assuming clear-sky conditions. The effect of the ozone hole is apparent. b. Variability computed under all-sky conditions. Clouds lead to a significant increment in the variability at Escudero. 


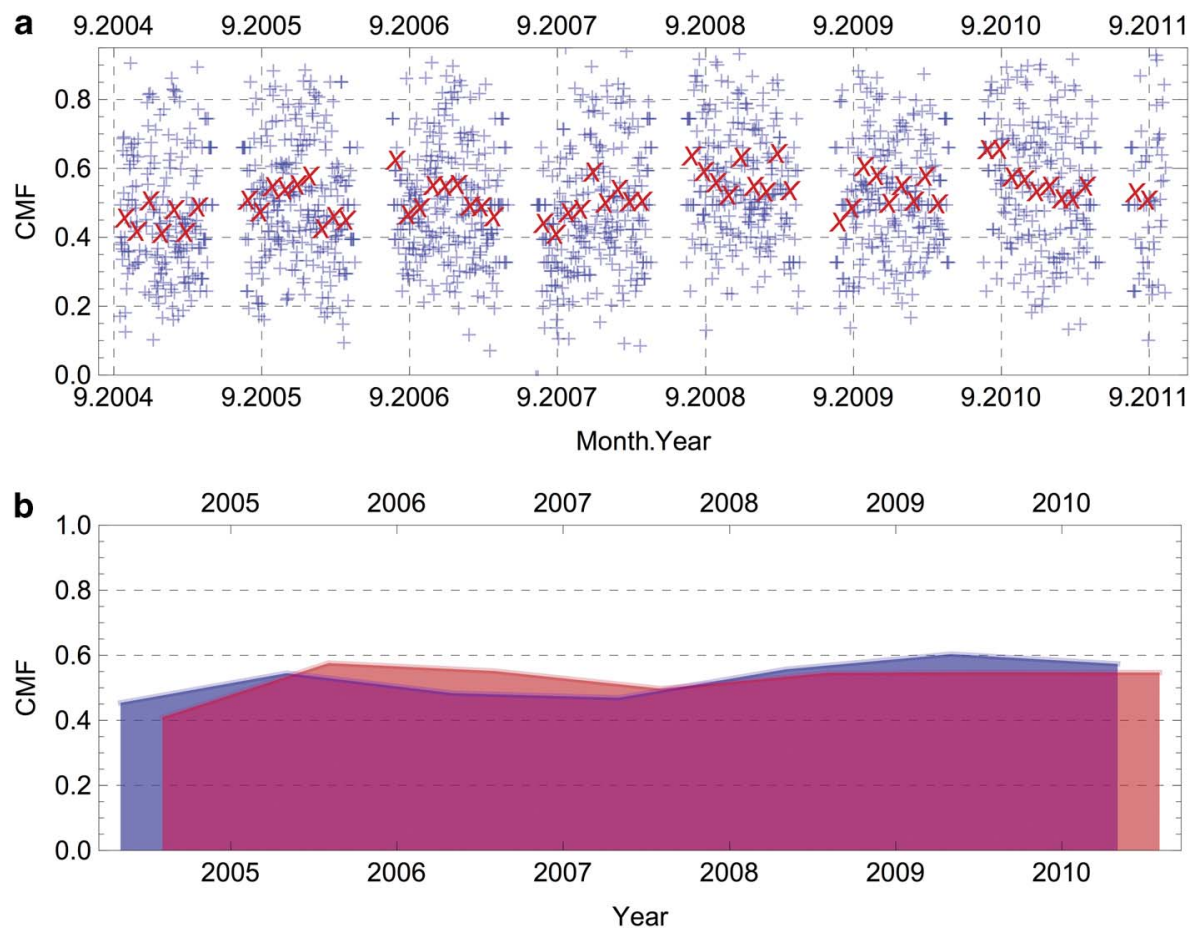

Fig. 5. a. UV index (UVI)-based cloud modification factor (CMF) at Escudero. The number 9 in the axis labels denotes September. The blue crosses indicate the daily $\mathrm{CMF}$ values at Escudero, and the red crosses the monthly averages. b. Monthly averages of the CMF data at Escudero computed for January (red line) and for October (blue line). approach unity close to the poles (Wuttke et al. 2006), albedo typically ranges between 0.6 and 0.95 at the nearby Palmer Station between August and November; after melting of snow and sea ice, albedo varies between 0.3 and 0.5 (Bernhard et al. 2005).

\section{Ground-based measurements}

Although some of the characteristic of the UV irradiance at Escudero can be described by using OMI-derived estimates, we gathered additional information by carrying out ground-based measurements. These quality-controlled spectral measurements were performed in January 2011 by using a double monochromator-based spectroradiometer (henceforth referred to as USACH spectroradiometer), normally based at the Universidad de Santiago de Chile (USACH, Chile). This instrument was set to sample the irradiance every $1 \mathrm{~nm}$ in the range $280-600 \mathrm{~nm}$. The scans were carried at a $30 \mathrm{~min}$ interval.

The USACH spectroradiometer consists of a double monochromator Bentham DMc150F-U, $150 \mathrm{~mm}$ focal length, fixed slits with gratings $\left(1800 \mathrm{~g} \mathrm{~mm}^{-1}\right)$ and a photomultiplier (PMT) as detector. The input optics and the double monochromator are connected by using UV transmitting fibre optic. The system was operated within a weather-proof box. This measuring system is meant to comply with NDACC specifications (see Seckmeyer et al. 2001). Attending to NDACC recommendations the stability of our ground-based spectral measurements was checked by using a set of halogen lamps.

\section{Data analysis}

Ozone

Figure 1a shows the OMI-derived total ozone column at Escudero over the period 2004-11. Because of the very high SZA during the polar winter, few data can be retrieved for May and for July, and no OMI readings are available for June. As shown in Fig. 1a, annually in spring, the ozone hole phenomenon leads to significant variations in the ozone values (see blue crosses in Fig. 1a).

The variability of ozone data (taken as the standard deviation of the OMI-derived estimates) ranges between $6 \%$ in January and 30\% in October (Fig. 1b). The effect of the ozone hole over monthly averages is less apparent (see red crosses in the Fig. 1a). However, as shown in Table I, the average of the OMI-derived total ozone column in September (233 DU) is typically about $25 \%$ lower than in December (305 DU). The lowest ozone value (about 120 DU) occurs in September.

Figure 1a confirms previous findings concerning the fact that at the edge of Antarctica the ozone depletion starts/finishes earlier and has a smaller intensity with respect to the sites located deeper inside the continent (e.g. Kuttippurath et al. 2010). For example, at Escudero the average of ozone values computed for October is roughly similar to the average computed for August (Table I). In contrast, ozone depletion at South Pole lasts up to November-December (e.g. Grooß et al. 2011) with minimum ozone values often below 100 DU in October. 

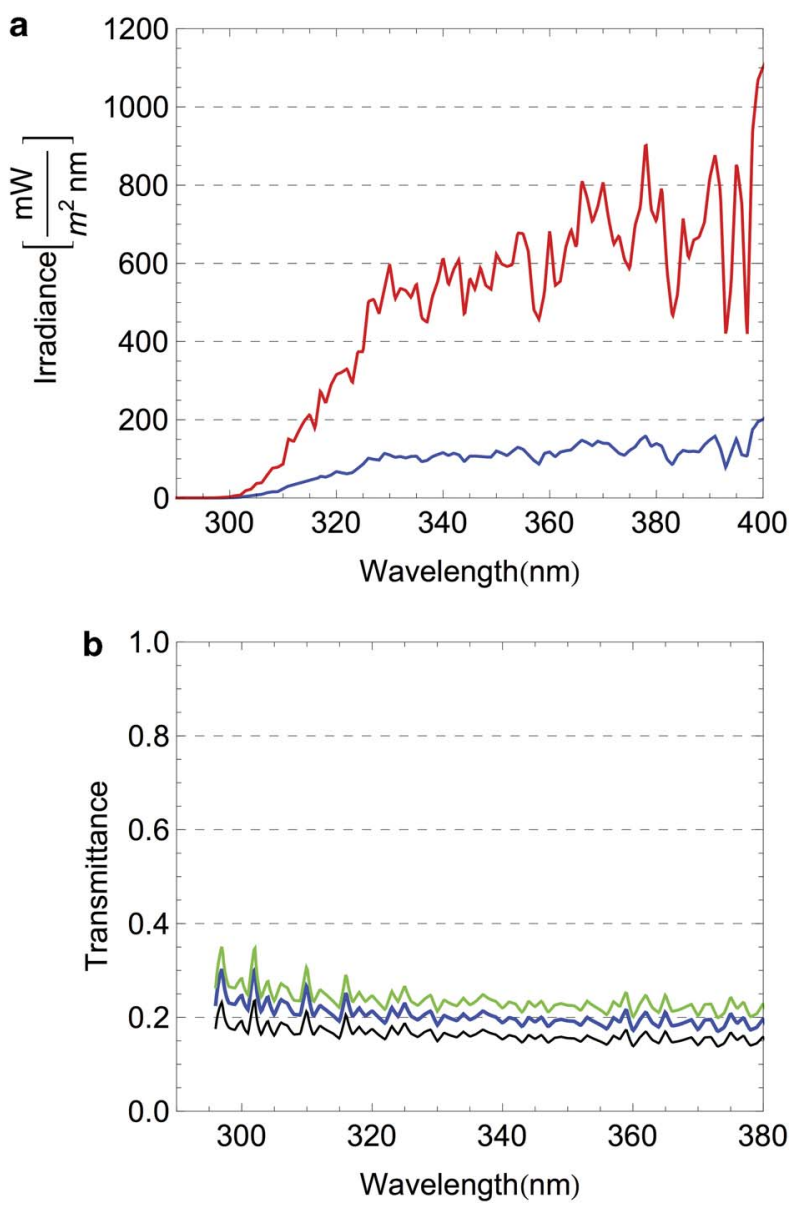

Fig. 6. a. Spectral UV irradiance measured at Escudero on 23 January 2011 (12h00 local time (LT)) under nearly homogeneous cloud cover (blue line), and the corresponding spectral UV irradiance computed by using the UVSPEC model assuming cloudless conditions (red line).

b. Transmittance of nearly homogeneous cloud cover on 23 January 2011. Colour indicates the time: 10h00 LT (black), $12 \mathrm{~h} 00$ LT (blue), 14h00 LT (green).

By comparing the variability in the total ozone column computed for January with the variability computed for October, we conclude that the ozone hole leads to a significant increment in the variability of ozone at Escudero. As shown in Table I, the variability of the total ozone column in spring is significantly greater than the variability in summer. For example, the variability computed for October $(30 \%)$ is roughly five times greater than for January $(6 \%)$.

We compared the ozone estimates retrieved from OMI, with the ozone computed from our ground-based spectral measurements carried out at Escudero Station in January 2011. Ozone was computed from our global irradiance measurements by applying the method described by Stamnes et al. (1991). This method is based on the comparison of measured global irradiance ratios at two wavelengths in the
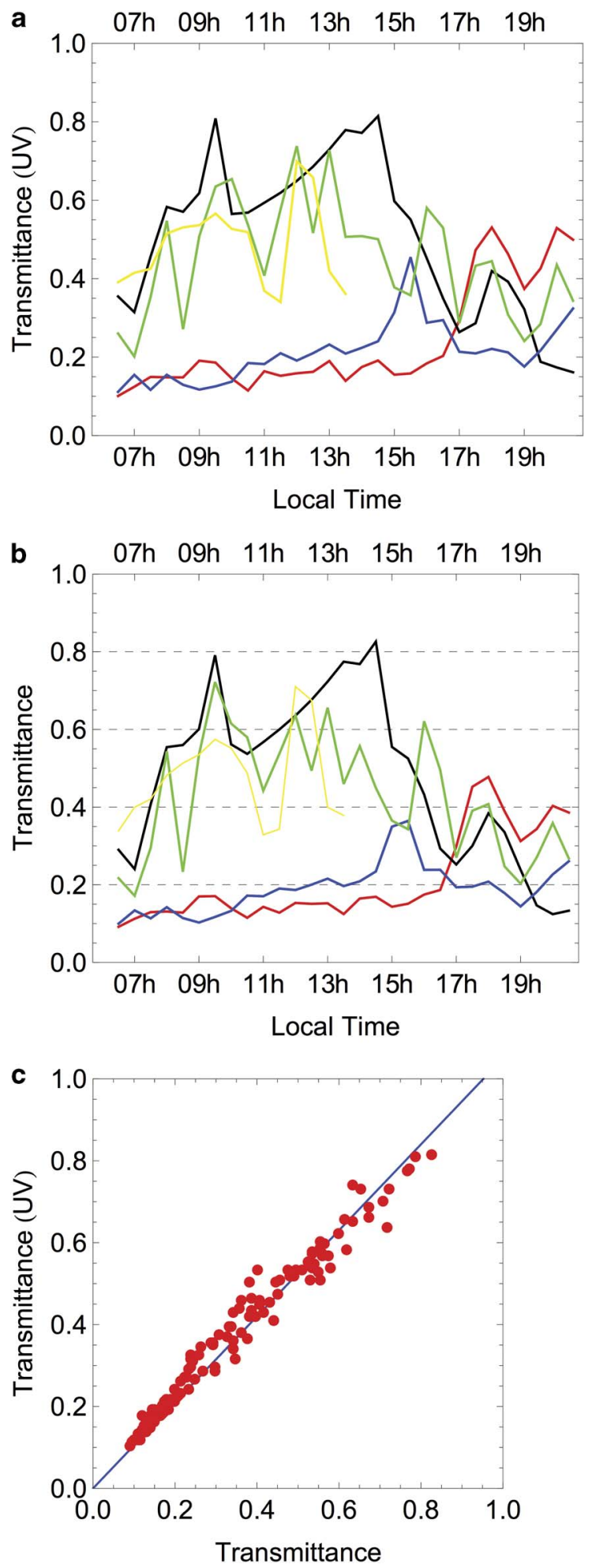

Fig. 7. Clouds transmittance computed from ground-based measurements and from UVSPEC model outcomes: $\mathbf{a}$. at the $280-400 \mathrm{~nm}$ wavelength range, and $\mathbf{b}$. at the $400-600 \mathrm{~nm}$ wavelength range. Colour indicates the dates: 21 January (red), 22 January (black), 23 January (blue), 24 January (green), 25 January (yellow). c. Scatter plot of transmittances shown in a. and b. Blue line indicates the linear regression (slope $1.05, r^{2}=0.97$ ). 
UV part of the spectrum with a synthetic chart of this ratio computed for a variety of ozone values. One of the wavelengths should be appreciably absorbed by ozone compared with the other. Although several combinations are possible, our choices were 305 and $340 \mathrm{~nm}$.

Figure 2 shows the total ozone column progression on 21-24 January 2011 computed from our ground-based measurements at Escudero. Although the applied technique tends to increasingly overestimate the total ozone column for optically thicker clouds (see Mayer et al. 1998), our daily measurements at the overpass time are in good agreement with ozone estimates retrieved from OMI (see crosses in Fig. 2). Total ozone column computed from global UV spectra by using a similar methodology (Bernhard et al. 2003) were also found to be in good agreement with TOMS data at some Antarctic locations (i.e. Palmer, McMurdo and South Pole stations see Bernhard et al. 2005, 2006). These findings confirm the accuracy of satellite retrieval algorithms at this time of year.

\section{UV index}

Figure 3 shows the time series of the OMI-derived estimates of the UVI at noon. As shown in Fig. 3, annually in spring, the ozone hole phenomenon leads to high UVI values. During these months, the noon-time UVI typically varies between 2 and 5.5, but UVI values as high as 8 have been observed. Despite this significant variability, the effect of the ozone hole over monthly averages was less apparent over the period 2004-11 (see black crosses and blue crosses in Fig. 3), except during spring 2009 when very high averages were computed under both clear-sky conditions and all-sky conditions. As shown in Fig. 3, UVI estimates reached extreme values in November 2009: that year the average of UVI estimates computed for November was about $20 \%$ greater than the average for the same month over the five preceding years. Nevertheless, in general terms monthly average of UV data computed for spring (under the influence of the ozone hole phenomenon) were found to be $20-30 \%$ greater than those expected without the influence of the ozone hole.

In general, the interannual changes of the Antarctic ozone concentration depend on the stratospheric temperatures in such a way that colder temperatures favour ozone depletion via increased occurrence of polar stratospheric clouds. Nevertheless, from the mid-nineties ozone has stabilized because of its saturation, i.e. due to the complete destruction of ozone over a broad vertical layer in the lower stratosphere (e.g. Newman et al. 2006). Therefore, its interannual variability is currently mainly driven by dynamics. Indeed, in November the Antarctic temperatures were lower in 2006 than in 2009 (e.g. Kuttippurath et al. 2010), nevertheless at Escudero ozone values were smaller (and UVI values higher) in 2009 (see Figs 1 \& 3).
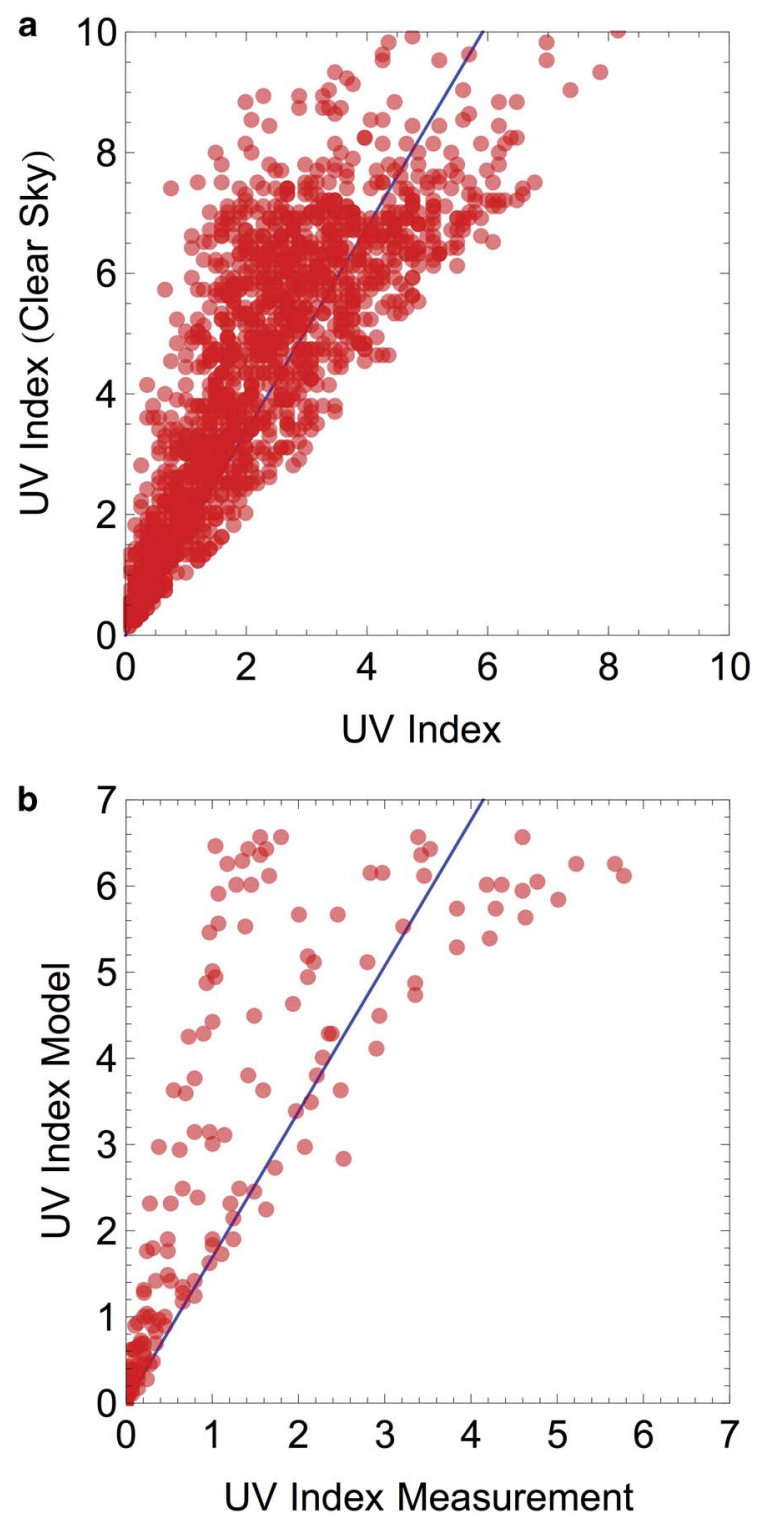

Fig. 8. a. Scatter plot of UV index (UVI) estimates retrieved from Ozone Monitoring Instrument (OMI) over the period 2004-11. Blue line indicates the linear regression (slope 1.69, $r^{2}=0.73$ ). b. Scatter plot of UVI values calculated from ground-based measurements (all-sky conditions) and from UVSPEC-modelled spectra (assuming clear-sky conditions). Blue line indicates the linear regression (slope 1.69, $\left.r^{2}=0.71\right)$.

Figure $4 \mathrm{a}$ shows the interannual variability of UVI values retrieved from OMI assuming clear-sky conditions for October and for January. By comparing the variability computed for January with the variability computed for October, we conclude that the ozone hole leads to a significant increment in the variability of UVI values computed assuming clear-sky conditions. As shown in Table I, the variability of the "clear-sky UVI" computed for October (34\%) is roughly three times greater than for 


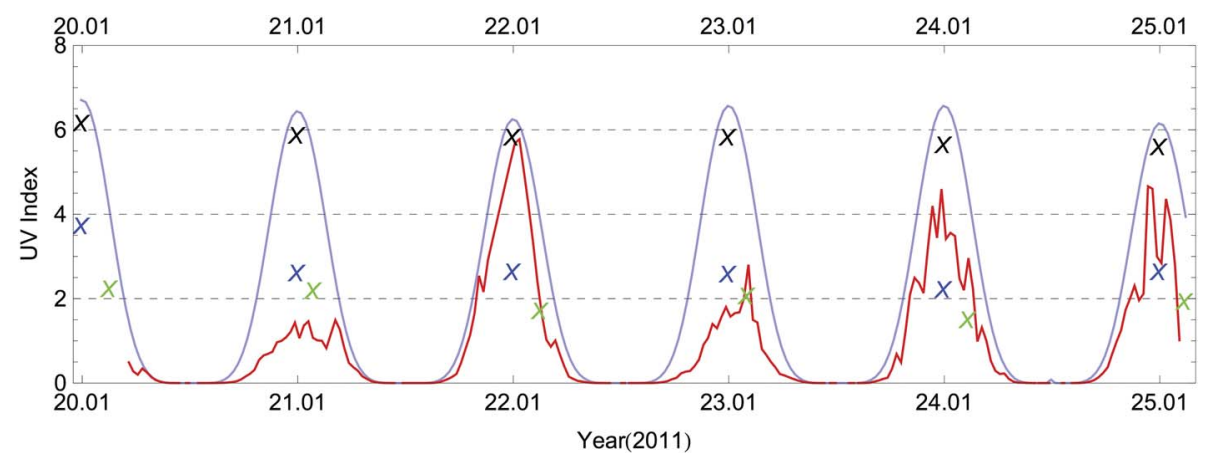

Fig. 9. UV index (UVI) on 20-25 January 2011 at Escudero Station computed from ground-based measurements (red line), from UVSPEC model outcomes (blue line) and from Ozone Monitoring Instrument (OMI) readings (crosses). Green crosses stand for the UVI estimates at overpass time, blue crosses indicate the UVI estimates at noontime, black crosses stand for the UVI estimates at noontime assuming clear-sky conditions.
January (11\%). Although this result was expected due to the similar differences in the variability of the ozone data reported in Data analysis, the figures significantly change when the cloud effect is considered.

As shown in Table I, the variability of UVI estimates under all-sky conditions computed for October (44\%) and for January $(33 \%)$ is significantly greater than under clearsky conditions. Figure $4 \mathrm{~b}$ shows the interannual variability of the UVI computed under all-sky conditions for October and for January. Since the variability under all-sky conditions (see Fig. 4b) is significantly higher than under clear-sky conditions (see Fig. 4a), we conclude that changes in the cloud cover (as well as in the ozone levels) drive the surface UVI at Escudero.

\section{Cloud effect}

Cloud effect on the transfer of radiation through the atmosphere can be weighed up by using the CMF. The CMF was initially computed as the ratio between UVI estimates under clear-sky conditions and UVI estimates under all-sky conditions: this CMF is henceforth referred to as UVI-based CMF. Attending to Krotkov et al. (2001), the CMF was also computed by using the surface reflectivity and the Lambertian equivalent reflectivity (LER) rendered by OMI: this CMF is henceforth referred to as LER-based CMF. As shown in Table I, the LER-based CMF values tend to be lower than the equivalent UVI-based CMF data. However, the variability of both is roughly the same.

Figure 5a shows the time series of the UVI-based CMF at Escudero. As shown in Fig. 5a, the variability of cloud cover leads to significant variations in the CMF, with values as low as 0.1 . The monthly average of CMF values at Escudero over the period 2004-11 typically ranged between 0.3 and 0.7 . These figures are significantly different from those found in the case of mid-latitude sites where on average clouds lead to an attenuating effect of $15-32 \%$ in the UV (Seckmeyer et al. 2008).

Figure $5 \mathrm{~b}$ shows that, over the period 2004-11, no significant differences are apparent in the averages of the UVI-based CMF at Escudero computed for October and for January. By comparing the monthly averages of the daily
CMF values computed from OMI data over the period 2004-11 (Table I), no seasonal change in the cloud effect was found either. Different figures have been reported in the case of the nearby Palmer Station. Based on groundbased measurements, Bernhard et al. (2005) reported cloud reductions on UV between 28\% (October and November) and $42 \%$ (February) compared to clear-sky levels.

By analysing the variability of the CMF at Escudero, we found no significant seasonal change. The typical variability of the UVI-based CMF is about 0.18 (Table I). This value is high considering that the $\mathrm{CMF}$ at Escudero ranged between 0.3 and 0.7 through the year. The high variability of the CMF leads to significant variations in the surface UV. This explains the large variability in the UVI data under all-sky conditions (see Fig. 4b) and is consistent with the measurement-based variability reported for the nearby Palmer Station (see Bernhard et al. 2005).

We checked if the variability of the CMF values (computed from satellite reading) agrees with the variability of the cloud transmittance computed from our ground-based spectral measurements. The transmittance was taken as being equal to the ratio between the measured UV spectrum and the corresponding potential spectrum assuming clear-sky conditions. The latter was computed by using the UVSPEC model.

Figure 6a shows the spectral UV irradiance measured at Escudero on 23 January 2011 under nearly homogeneous cloud cover compared with the corresponding potential spectral UV irradiance under cloudless conditions. The latter was computed by using the UVSPEC model. A strong cloud-linked attenuation is apparent. Spectra shown in Fig. 6a, and others measured on the same day, were used to build up Fig. 6b. As expected (see Seckmeyer et al. 1996), a wavelength-dependent transmittance was found, which was verified by comparing the cloud transmittance at 280-400 nm wavelength range (see Fig. 7a) with the cloud transmittance at $400-600 \mathrm{~nm}$ wavelength range (see Fig. 7b), both computed by using measured and modelled spectra. The strong temporal variability of the cloud cover at Escudero leads to significant variations through the day in the transmittances (Fig. 7a \& b). Figure $7 \mathrm{c}$ shows the scatter plot of the transmittances in 

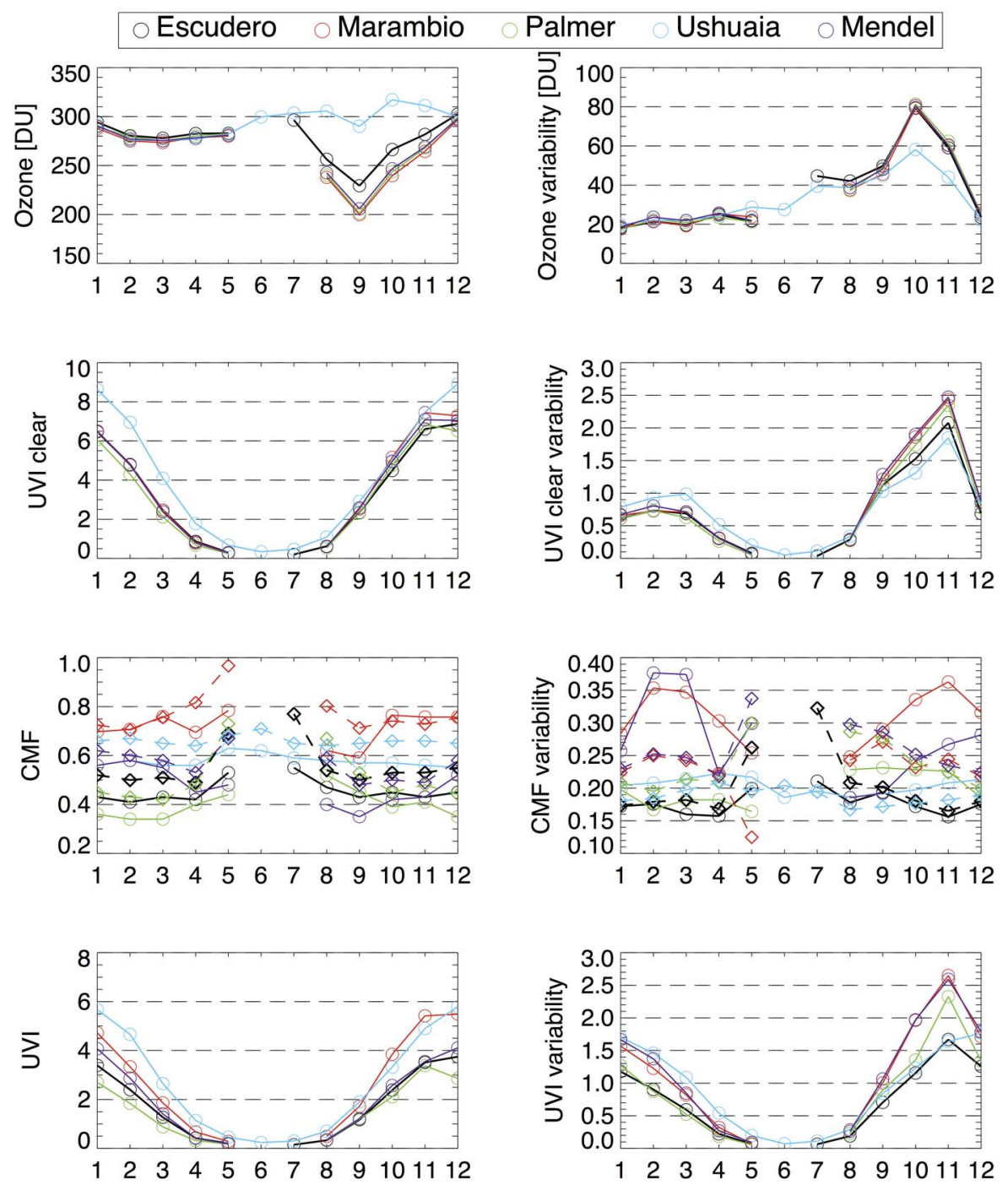

Fig. 10. Average (left column) and variability (right column) computed by using the Ozone Monitoring Instrument (OMI)-derived data over the period 2004-11 at Escudero Station, and at other nearby locations: Ushuaia $54.8^{\circ} \mathrm{S}, 68.3^{\circ} \mathrm{W}$; Mendel $63.8^{\circ} \mathrm{S},-57.9^{\circ} \mathrm{W}$; Marambio $64.2^{\circ} \mathrm{S}, 56.6^{\circ} \mathrm{W}$; and Palmer $64.8^{\circ} \mathrm{E}$, $64.1^{\circ} \mathrm{W}$. From top to bottom: ozone; UV index (UVI) under clear-sky conditions; cloud modification factor (CMF) (solid lines: Lambertian equivalent reflectivity (LER)-based; dashed lines: UVI-based); UVI under all-sky conditions; and surface albedo.

Fig. $7 \mathrm{a} \& \mathrm{~b}$. This plot confirms that transmittances tend to be greater in the UV.

Although the transmittances during the campaign were on average lower than the CMF values computed from satellite readings, the variability of transmittances in Fig. 7a \& b, was found to be in remarkable agreement with the variability of CMF values computed from satellite readings. The good consistency between the cloudlinked variability computed from satellite readings (over the period 2004-11), and the cloud-linked variability computed from measurements (carried out at a $30 \mathrm{~min}$ period during our relatively short campaign) is better depicted by Fig. 8. Figure 8a shows the scatter plot of the UVI estimates retrieved from OMI over the period 2004-11. Figure $8 \mathrm{~b}$ shows the scatter plot of UVI values computed from our measurements and from UVSPECcalculated spectra.

\section{Albedo factor}

Figure 9 shows the UVI values computed from spectra measured with the USACH spectroradiometer at a $30 \mathrm{~min}$ 
interval on 20-25 January 2011 at Escudero. Figure 9 also shows the UVI calculated from UVSPEC-computed spectra assuming clear-sky conditions. In addition, UVI estimates retrieved from OMI are also shown.

When compared at overpass time, differences between satellite estimates and ground-based measurements were found. This difference was expected due to the satellite limited spatial resolution, which is unable to capture the effects of local clouds (that, as discussed above, at Escudero showed significant temporal and spatial variations). Since the differences were probably due to the variability of cloud cover, satellite estimates sometimes overestimated the surface UVI by up to $50 \%$ (e.g. data on 21 January in Fig. 9) and sometimes underestimated it by up to $40 \%$ (e.g. data on 24 January in Fig. 9). As in previous efforts (e.g. Tanskanen et al. 2007a), the surface UVI measured at overpass time was on average during the campaign about $30 \%$ lower than OMI-derived estimates. When compared at noon, the difference between satellite products and ground-based measurements tends to increase because OMI algorithm applies no correction for the change in cloudiness, in ozone and in aerosols, between local noon and overpass time. In this case, satellite products sometimes overestimated the surface UVI by up to $70 \%$ (e.g. data on 21 January in Fig. 9) and sometimes underestimated it by up to $50 \%$ (e.g. data on 22 January in Fig. 9).

A nearly systematic difference between the OMI-derived and the UVSPEC-computed estimates of UVI was found. The UVI at noon computed assuming clear-sky conditions by using the UVSPEC model was always about $8 \%$ higher than OMI-derived estimates of UVI assuming clear-sky conditions (Fig. 9). This difference was again expected because at high latitude sites (e.g. Palmer, McMurdo and other stations in Antarctica) the climatological surface albedo used by OMI algorithm can be unrealistically small (Tanskanen et al. 2007b). Actually, we found out that satellite-derived estimates of UVI under clear-sky conditions in Fig. 9 can be reproduced by running the UVSPEC with an albedo equal to $20 \%$. However, the effective albedo at Escudero was significantly higher on 20-25 January 2011.

\section{Comparison with other Antarctic locations}

The average and variability (computed by using the daily data retrieved from OMI at Escudero Station over the period 2004-11) have been compared in Fig. 10 with the corresponding values computed from OMI-derived data at other nearby locations (Ushuaia $\left(54.8^{\circ} \mathrm{S}, 68.3^{\circ} \mathrm{W}\right)$, Mendel $\left(63.8^{\circ} \mathrm{S},-57.9^{\circ} \mathrm{W}\right)$, Marambio $\left(64.2^{\circ} \mathrm{S}, 56.6^{\circ} \mathrm{W}\right)$, and Palmer $\left.\left(64.8^{\circ} \mathrm{E}, 64.1^{\circ} \mathrm{W}\right)\right)$.

As shown in Fig. 10a, the strongest ozone depletion (occurring at Escudero in September) is usually about 30 DU higher than at other Antarctic stations while its variability is similar (see Figure 10b). As shown in Figure $10 \mathrm{~d} \& \mathrm{~h}$, the absolute variability of UVI estimates reaches its maximum in November. However, as pointed out above, the relative variability of UVI estimates reaches its maximum in September (Table I). Indeed, although the absolute variability computed for September is lower than for November, small absolute changes lead to significant relative changes in the relatively low UVI values registered in September.

Despite the proximity of the stations, significant differences in the cloud cover can be observed. The monthly average of the CFM values ranges between 0.4 and 0.7 (Fig. 10e). The LER-based CMF values tend to be lower than the equivalent UVI-based CMF data (Fig. 10e). This difference becomes larger under high $\mathrm{SZA} /$ surface albedo conditions.

Since a portion of the observed reflectivity may be incorrectly interpreted by the satellite as cloud cover, the OMI-derived estimates of the CMF tend to be more uncertain under conditions of high albedo. However, as shown in Fig. 10i, the surface albedo is relatively low at Escudero. We conclude that the low reflectivity associated with the site makes the CMF estimates at Escudero less uncertain.

\section{Summary and conclusions}

We have described some of the characteristic of the surface UV at Escudero Station. Most of our conclusions are based on estimates retrieved from OMI. The consistency of satellitederived data was checked by using ground-based spectral measurements carried out under controlled conditions in January 2011. We found a good agreement between the ozone estimates retrieved from OMI, and the ozone values computed from our ground-based measurements. Moreover, significant differences were found when comparing UVI estimates retrieved from OMI and ground-based measurements. However, these differences were expected due to the limited spatial resolution of the satellite that is unable to capture the local effects of clouds. As pointed out above, clouds at Escudero showed significant temporal and spatial variations. The surface UVI measured at overpass time was on average during the campaign about $30 \%$ lower than UVI estimates retrieved from OMI.

Despite the differences when comparing satellite-derived data and ground-based measurements, we found a remarkable agreement when comparing the corresponding variability. The detected variations in the ozone and in the CMF (both retrieved from OMI) are consistent with the variations observed in our ground-based spectral measurements.

Based on OMI-derived data, we found that surface UV at Escudero is driven by ozone and clouds. Antarctic ozone depletion leads to the significant variability of the total ozone column at Escudero in spring. The variability of ozone data ranges between $6 \%$ in January and $30 \%$ in October. The effect of the ozone hole over monthly 
averages is also significant. The average of the OMIderived data computed for September (233 DU) is typically about 25\% lower than for December (305 DU). The lowest ozone values (about 120 DU) typically occur in September.

Clouds at Escudero are more frequent and have a larger optical depth compared with other Antarctic sites. By analysing the variability of the OMI-derived estimates of the CMF, we found no significant seasonal change at Escudero. The typical variability of the CMF is about 0.18 . This value is significantly high considering that the CMF at Escudero typically ranges between 0.3 and 0.7 through the year. The high variability of both the CMF data and the total ozone column, leads to the significant variations in the surface UV at Escudero.

Although the variability of surface UV data is always typically greater than $30 \%$ at Escudero, it may reach values greater than $50 \%$ in spring (under the influence of the ozone hole phenomenon). Linear regression analyses did not indicate statistically significant trends in UV.

\section{Acknowledgements}

The support of CONICYT-DAAD (Preis 257-2010), CONICYT-BMBF (Preis 236-2010), CONICYT-ANILLOS (Preis ACT98), FONDECYT (Preis 1120639, Preis 3110159 and Preis 1120764), the Chilean Antarctic Institute (INACH), the Millennium Scientific Initiative (P10-061-F), CEDENNA, UTA-Project 8750-12, USACH-DICYT and UTFSM-DGIP is gratefully acknowledged. We also thank the reviewers for their constructive comments.

\section{References}

Angiel, P.J., Ротоскi, M. \& Biszczun-Jakubowska, J. 2010. Weather condition characteristics at the H. Arctowski Station (South Shetland Islands, Antarctica) for 2006, in comparison with multi-year research results. Miscellanea Geographica, 14, 79-89.

Bernhard, G., Booth, C.R. \& Ehramian, J.C. 2004. Version 2 data of the National Science Foundation's Ultraviolet Radiation Monitoring Network: South Pole. Journal of Geophysical Research, 10.1029/ 2004JD004937.

Bernhard, G., Booth, C.R. \& Ehramjian, J.C. 2005. UV climatology at Palmer Station, Antarctica. In Bernhard, G., Slusser, J.R., Herman, J.R. \& GAO, W., eds. Ultraviolet ground- and space-based measurements, models, and effects $V$. Proceedings of the Society of Photo-optical Instrumentation Engineers. Bellingham, WA: SPIE, 322 pp.

Bernhard, G., Booth, C.R. \& Ehramitan, J.C. 2010. Climatology of ultraviolet radiation at high latitudes derived from measurements of the National Science Foundation's Ultraviolet Spectral Irradiance Monitoring Network. In GaO, W., Schmoldt, D.L. \& Slusser, J.R., eds. UV radiation in global climate change: measurements, modelling and effects on ecosystems. New York: Springer, $550 \mathrm{pp}$.

Bernhard, G., Booth, C.R. \& McPeters, R.D. 2003. Calculation of total column ozone from global UV spectra at high latitudes. Journal of Geophysical Research, 10.1029/2003JD003450.

Bernhard, G., Booth, C.R., Ehramjian, J.C. \& Nichol, S.E. 2006. UV climatology at McMurdo Station, Antarctica, based on version 2 data of the National Science Foundation's Ultraviolet Radiation Monitoring Network. Journal of Geophysical Research, 10.1029/2005JD005857.
Buchard, V., Brogniez, C., Auriol, F., Bonnel, B., Lenoble, J., Tanskanen, A., Bojkov, B. \& Veefkind, P. 2008. Comparison of OMI ozone and UV irradiance data with ground-based measurements at two French sites. Atmospheric Chemistry and Physics, 8, 4517-4528.

Chol, T., Lee, B.Y., Kim, S.J., Yoon, Y.J. \& Lee, H.C. 2008. Net radiation and turbulent energy exchanges over a nonglaciated coastal area on King George Island during four summer seasons. Antarctic Science, 20, 99-112.

Cordero, R.R., Seckmeyer, G., Pissulla, D., DaSilva, L. \& Labbe, F. 2007. Uncertainty evaluation of the spectral UV irradiance evaluated by using the UVSPEC Radiative Transfer Model. Optics Communications, 276, 44-53.

Cordero, R.R., Seckmeyer, G., Pissulla, D., DaSilva, L. \& Labbe, F. 2008. Uncertainty evaluation of spectral UV irradiance measurements. Measurement Science and Technology, 19, 1-15.

Dahlback, A. \& Stamnes, K. 1991. A new spherical model for computing the radiation field available for photolysis and heating at twilight. Planetary and Space Science, 39, 671-683.

Damiani, A., De Simone, S., Rafanelli, C., Cordero, R.R. \& Laurenza, M. 2012. Three years of ground-based total ozone measurements in Arctic: comparison with OMI, GOME and SCIAMACHY satellite data. Remote Sensing of Environment, 27, 162-180.

Farman, J.C., Gardiner, B.G. \& Shanklin, J.D. 1985. Large losses of total ozone in Antarctica reveal seasonal C1Ox/NOx interaction. Nature, 315, 207-210.

Flemming, J., Inness, A., Jones, L., Eskes, H.J., Huijnen, V., Schultz, M.G., Stein, O., Cariolle, D., Kinnison, D. \& Brasseur, G. 2011. Forecasts and assimilation experiments of the Antarctic ozone hole 2008. Atmospheric Chemistry and Physics, 11, 1961-1977.

Gröbner, J., Blumthaler, M., Kazadzis, S., Bais, A., Webb, A., Schreder, J., Seckmeyer, G. \& Rembges, D. 2006. Quality assurance of spectral solar UV measurements: result from 25 UV monitoring sites in Europe, 2002 to 2004. Metrologia, 43, S66-S71.

Grooß, J.-U., Brautzsch, K., Pommrich, R., Solomon, S. \& Müller, R. 2011. Stratospheric ozone chemistry in the Antarctic: what determines the lowest ozone values reached and their recovery? Atmospheric Chemistry and Physics, 11, 12 217-12 226.

GueYMARD, C.A. 2004. The sun's total and spectral irradiance for solar energy applications and solar radiation models. Solar Energy, 76, 423-453.

Ialongo, I., Arola, A., Kujanpä̈̈, J. \& Tamminen, J. 2011. Use of satellite erythemal UV products in analysing the global UV changes. Atmospheric Chemistry and Physics, 11, 9649-9658.

Krotkov, N.A., Herman, J.R., Bhartia, P.K., Fioletov, V. \& Ahmad, Z. 2001. Satellite estimation of spectral surface UV irradiance 2. Effects of homogeneous clouds and snow. Journal of Geophysical Research, 106, $11743-11759$.

Kuttippurath, J., Goutall, F., Pommereau, J.-P., Lefève, F., Roscoe, H.K., Pazmiño, A., Feng, W., Chipperfield, M.P. \& Godin-Beekmann, S. 2010. Estimation of Antarctic ozone loss from ground-based total column measurements. Atmospheric Chemistry and Physics, 10, 6569-6581.

Laska, K., Budik, L., Budikova, M. \& Prosek, P. 2011. Method of estimation of solar UV radiation in high latitude location based on satellite ozone retrieval with improved algorithm. International Journal of Remote Sensing, 32, 3165-3177.

Laska, K., Prosek, P., Budik, L., Budikova, M. \& Milinevsky, G. 2010. Estimation of solar UV radiation in Maritime Antarctica using nonlinear model including cloud effects. International Journal of Remote Sensing, 31, 831-849.

Mayer, B. \& Kylling, A. 2005. Technical note: the libRadtran software package for radiative transfer calculations - description and examples of use. Atmospheric Chemistry and Physics, 5, 1855-1877.

Mayer, B., Kylling, A., Madronich, S. \& Seckmeyer, G. 1998. Enhanced absorption of UV radiation due to multiple scattering in clouds: experimental evidence and theoretical explanation. Journal of Geophysical Research, 103, 31 241-31 254. 
McKinlay, A.F. \& Diffey, B.L. 1987. A reference action spectrum for ultraviolet induced erythema in human skin. Commission Internationale de l'Eclairage Journal, 6, 17-22.

Newman, P.A., Nash, E.R., Kawa, S.R., Montzka, S.A. \& Schauffler, S.M. 2006. When will the Antarctic ozone hole recover? Geophysical Research Letters, 10.1029/2005GL025232.

Seckmeyer, G., Erb, R. \& Albold, A. 1996. Transmittance of a cloud is wavelength-dependent in the UV range. Geophysical Research Letters, 23, 2753-2755.

Seckmeyer, G., Bais, A., Bernhard, G., Blumthaler, M., Booth, C.R., Disterhoft, P., Eriksen, P., McKenzie, R.L., Miyauchi, M. \& Roy, C. 2001. Instruments to measure solar ultraviolet radiation. Part 1. Spectral instruments. WMO-GAW Report No. 125. Geneva: World Meteorological Organization, $30 \mathrm{pp}$.

Seckmeyer, G., Pissulla, D., Glandorf, M. et al. 2008. Variability of UV irradiance in Europe. Photochemistry and Photobiology, 84, $172-179$.

Stamnes, K., Slusser, J. \& Bowen, M. 1991. Derivation of total ozone abundance and cloud effects from spectral irradiance measurements. Applied Optics, 30, 4418-4426.

TANSKANEN, A. 2004. Lambertian surface albedo climatology at $360 \mathrm{~nm}$ from TOMS data using moving time-window technique. Proceedings of the $X X$ Quadrennial Ozone Symposium, 1-8 June 2004, Kos, Greece, 1159-1160.
Tanskanen, A. \& Manninen, T. 2007b. Effective UV surface albedo of seasonally snow-covered lands. Atmospheric Chemistry and Physics, 7 , 2759-2764.

Tanskanen, A., Krotkov, N.A., Herman, J.R. \& Arola, A. 2006. Surface ultraviolet irradiance from OMI. IEEE Transactions on Geoscience and Remote Sensing, 44, 1267-1271.

Tanskanen, A., Lindfors, A., Mä̈̈tтÄ, A. et al. 2007a. Validation of daily erythemal doses from Ozone Monitoring Instrument with ground-based UV measurement data. Journal of Geophysical Research, 10.1029/2007JD008830.

Weihs, P., Blumthaler, M., Rieder, H.E., Kreuter, A., Simic, S., Laube, W., Schmalwieser, A.W., Wagner, J.E. \& Tanskanen, A. 2008. Measurements of UV irradiance within the area of one satellite pixel. Atmospheric Chemistry and Physics, 8, 5615-5626.

WHO (World Health Organization). 2002. Global solar UV index: a practical guide. Geneva: World Health Organization, 18 pp.

WMO (World Meteorological Organization). 2011. Scientific assessment of ozone depletion: 2010. Global Ozone Research and Monitoring Project-Report No. 52. Geneva: World Meteorological Organization, $516 \mathrm{pp}$.

Wuttke, S., Seckmeyer, G. \& Koenig-Langlo, G. 2006. Measurements of spectral snow albedo at Neumayer, Antarctica. Annals of Geophysics, 24, 7-21. 